\title{
Title: A utilitarian perspective of social and medical contributions to three illustrative conditions, and recent UK NHS policy initiatives.
}

\section{Short title: A utilitarian perspective.}

Dr Hugh Middleton, Senior Lecturer and Honorary Consultant Psychiatrist, and Ian Shaw, Professor of Health Policy, University of Nottingham.

School of Sociology and Social Policy, University of Nottingham,

University Park,

Nottingham

NG7 2RD

$(6,670$ words, excluding title and references)

Correspondence to:

Dr Hugh Middleton

School of Sociology and Social Policy, University of Nottingham,

University Park,

Nottingham

NG7 2RD

Tel: 01159691300

Fax: 01159555352

email : hugh.middleton@nottingham.ac.uk 


\section{Title: A utilitarian perspective of social and medical contributions to three illustrative conditions, and recent UK NHS policy initiatives.}

\section{ABSTRACT: \\ Background}

To date debate concerning the relative merits of social and medical sciences has been largely academic.

\section{Aims}

To outline and critically appraise a utilitarian approach to mental health research that reflects a critical realist perspective.

\section{Method}

Consideration of the relative utility of differing approaches to illustrative "psychiatric" disorders, and recent policy initiatives.

\section{Results}

Socially relevant outcomes of Bipolar Affective Disorder are determined by influences that operate independently of the characteristic instability of mood. There is now a highly specific and effective psychological treatment for Panic Disorder. Its benefits are still not fully exploited because of continuing lay and professional focus upon the condition's social manifestations. Great numbers of people presenting in primary care are unhelpfully caused to adopt the role of "patient" due to practices limiting the professional response to a medical one. Such practices reflect public and professional perceptions of the nature of "mental health difficulties" much more than they do the achievements of medicine. Recent policy-supporting initiatives influencing UK NHS mental health services are much more likely to be supported by social sciences than by medical research.

\section{Conclusions}

There is considerable scope for a contribution to applied mental health research from frameworks and methodologies that are rooted in a social sciences perspective. 


\section{INTRODUCTION:}

The relationship between Social Science and Psychiatry has been uneasy for much of the last half-century (Pilgrim \& Rogers, 2005). At its starkest the relationship is a stereotyped distinction between mechanistic approaches to individual dysfunction (the medical model) and a more pragmatic approach to mental health difficulties based upon social causes and consequences, and the lived experience of those involved (the social care model). Most commentaries focus upon intellectual dimensions of the distinction. However, the distinction also finds expression in competing, resource-determining claims between communities, or networks, of practitioners and investigators. Thus the intellectual debate has to be informed by acknowledgment of the fact that knowledge itself is a socially determined phenomenon (e.g. Barnes et al., 1996; Law \& Mol, 2002).

The sources, merits and limits of a medical approach to mental and emotional distress have provoked commentary and continue to do so, In their different ways Jones (1972) and Scull (1989) offer historical reflections on the role psychiatry has played in processes mediating social segregation, and in social policy. Amongst others, Busfield (1989) offers an account of ways in which this background has shaped current practices and there is strong evidence that the use of current mental health legislation is socially discriminating (Shaw et al., 2006).

Callahan \& Berrios (2005) review the ways in which "going to the doctor" and obtaining a diagnosis of "depression" has become common amongst the emotionally distressed. There are concerns that opinion-forming publications encouraging this may be influenced by sponsorship from the pharmaceutical industry (Healy \& Cattell, 2003), and voices from within psychiatry and psychology draw attention to the shortcomings of a medical approach to these issues (Bentall, 2006; Bracken \& Thomas, 2001; Double, 2002).

Critiques of an approach to mental and/or emotional distress framed in medical terms can be outlined as follows; 
- The approach has become dominant for a complex set of economic, historical and social reasons, not just because medical science has opened up a radically more effective set of treatments. This contrasts with other contemporaneous advances, such as the development of antibiotics, vaccines, or safe and effective means of controlling blood pressure.

- There is often a difference between lay and professional views of psychiatry, and as a result it is legitimate to question the validity of a medical approach to mental and emotional distress. It is openly criticised by academic and other commentators, especially those speaking on behalf of individual sufferers, or from a background of personal experience. This is in stark contrast to the unified respect commentators have for most other areas of medical endeavour.

- Victims of mental and/or emotional distress, and services provided for them provoke ambivalent responses. "Psychiatric patients" are simultaneously pitied and regarded as threatening. Reflecting their role as agencies of social control, "psychiatric services" are simultaneously viewed as caring and custodial. Again, this contrasts with public reactions to, say, sick children and paediatricians. Rather than being seen as helpful, psychiatric services are considered by some users as damaging; indeed some refer to themselves as 'survivors'.

In the United Kingdom, present times see a growing return to concerns about the shortcomings of an orthodox medical approach to the needs and nature of these problems. A much more consumerist approach to public services in general, and health care provision in particular, has encouraged mental health policy makers and practitioners to look again at their clients' experiences (Department of Health 2006a). It is now publicly recognised that mental health problems are a major cause of disability and economic dependency, and there is a search for service developments that will deliver more socially determined outcomes such as a return to work, personal autonomy and growth, reduced dependency, and personal satisfaction or "Happiness" (Layard, 2005). This is a major shift, no less significant than the move away from an institutional approach to mental health problems that began some fifty years ago, and no less 
A utilitarian perspective

complex in its causes and likely consequences. Understanding it demands an epistemological perspective that can accommodate such complexity. In this paper we argue for the benefits of a pluralist approach to mental health research and practice, in particular reconciliation of the seemingly opposed but possibly complementary roles of medical and social science perspectives. As others have suggested (Pilgrim \& Rogers, 2005), one such approach is critical realism.

\section{A CRITICAL REALIST/UTILITARIAN PERSPECTIVE:}

As with any set of polarised positions, competition between social science and medicine for the "psychological difficulties" territory reflects the partial nature of both positions. A simple illustration of critical realism is the Sufi parable of blind men encountering an elephant, and declaring it to be "like" something similar to the part that they have encountered; a snake to the one who encountered the trunk, a tree to the one that encountered a leg and so on. In more formal terms this is the position expounded by Bhaskar and others of the critical realism school (Bhaskar, 1975). Critical realism maintains that there is an objectively, potentially knowable, independent reality, but at the same time acknowledges the constructive roles of context, perception and cognition. When applied to the philosophy of science this highlights how empiricists' focus upon approaches depending upon controllable phenomena that can be manipulated to produce particular outcomes, is only one form of observation. It does not, for instance, enable the study of emergent properties so central to an understanding of human behaviour and its vagaries (Bateson, 1972). By acknowledging an objectively, potentially knowable reality as well as the constructive roles of context and cognition, critical realism meets some of the criticisms more absolutely constructivist approaches to knowledge present. At the same time it respects the validity of differing approaches to the development of knowledge. No investigator, be they a medical or a social scientist, can justifiably claim absolute ownership of any territory of investigation; their activities can only advance what is known about the subject of study from the perspective of their own methodologies and conceptual frameworks. 
A utilitarian perspective

Within a medical framework instances of mental and/or emotional distress are classified using one or other of the diagnostic schemes; the International Classification of Diseases, ICD, or the Diagnostic and Statistical Manual, DSM. These classifications are, essentially, exercises in pattern recognition. They clarify the presence or absence of features required to fulfil certain explicit criteria. Where criteria are met, a "diagnosis" is made. Thus "diagnosis" is not a statement of pathological fact but an emergent property of a particular constellation of signs and symptoms. For instance, it is not difficult to make a "diagnosis" of romantic love ... either as an observer or a participant. Doing so doesn't presuppose recognition of an abnormality and neither does it invalidate the myriad forms romantic love can take, but it does identify an emergent property with a fairly predictable course and consequences. Similarly, where psychiatric "diagnosis" identifies a set of disabling phenomena that are known to be susceptible to a particular intervention, then it is a useful heuristic.

Within a framework of social care, an instance of mental and/or emotional distress is likely to be considered ideographically; as a unique phenomenon reflecting the subject's personal propensities, background and context. Distress and disability are considered to be the direct consequence of interactions between these without reference to derived, higher order abstractions. Academic endeavours reflect these differing approaches, broadly respecting either the classificatory, diagnostic framework of the medical tradition or the ideographic framework of social care.

Exploitation of research findings in pursuit of solutions to medical and social problems is an applied science. The purpose of investigation is not just the advancement of knowledge, but also the fulfilment of a particular set of ends. Thus, the utility of a particular approach in achieving those ends is a relevant consideration. The critical realist would argue that all methodologies and conceptual frameworks are equally valid from an epistemological perspective, and that their utility is defined by context, rather than by an externally referenced hierarchy.

From this point of view medical and social sciences have equal merit as purely academic endeavours, but as guides to public policy (including investment in research), utility and 
A utilitarian perspective

relevance have to be taken into consideration. Our thesis is that each research tradition has a contribution to make, but that their relative utility varies from condition to condition. The practitioner's perspective is different from the theorist's, and where a particular set of phenomena indicate a "diagnosis" that points to an effective treatment, then the utilitarian advantages of a "medical" approach have to be acknowledged. With its origins in systems of classification that justified incarceration and its current susceptibilities to the pharmaceutical industry, the practice of psychiatry is probably unhelpfully over-committed to a diagnostic/medical approach to mental and/or emotional distress, and there is undoubted over-use of the diagnostic approach. Nevertheless we argue that it is unduly dogmatic to dismiss it altogether. We illustrate this now by considering the differing contributions medical and social science have made and might make to each of three commonly encountered forms of distress.

\section{BIPOLAR AFFECTIVE DISORDER:}

"BAD" is characterised by episodes of disturbed mood. Research grounded in a biomedical framework has established that the disorder has a well defined phenotype which is readily recognisable and defined by the occurrence of repeated hypo-manic and major depressive episodes. There is a significant difference between the monozygotic (70\%) and the dizygotic (23\%) twin concordance rate. Genomic linkage techniques have identified a link with dopamine metabolism (Barrett et al., 2003). Dopamine is a neurotransmitter which is associated with appetitive and rewarding behaviour and thus a conceptual link to mood regulation can be made, as well as the statistical associations that strongly point to an inheritable contribution.

The condition has all the characteristics of an illness and it is generally treated as such, with partially effective medications and a variety of adjunctive psychological therapies. Most cultures are quick to respond to the bipolar patient in a paternalistic way, committing them to hospital for treatment without consent if other less coercive approaches are not effective. There is probably no other psychological condition less controversially considered an "illness", and for the majority of sufferers and their carers 
A utilitarian perspective

or close associates this provides an acceptable modus vivendi; but is this a full and adequate description?

The older term, "Manic-Depressive" conjures up a more socially charged image and communicates a more social perspective. Google's Wikipedia lists some 65 prominent historical and contemporary figures who are considered Manic-depressives, including Frank Bruno, Winston Churchill, Charles Dickens, Jimmy Hendricks, Vivien Leigh, Spike Milligan, Isaac Newton and Vincent Van Gogh. The accuracy with which these contemporary or post hoc diagnoses concur with ICD-10 criteria is variable, but the communicated image of a flawed and somewhat tragic genius is a recurrent theme. Furthermore the association with creativity does appear to be more than co-incidental (Redfield Jamison, 1993).

Unfortunately the majority of 'Manic-Depressives' do not enjoy the full benefits of becoming a creative genius. Suicide is many times more common than in the general population, and there are comparable increases in rates of marital breakdown, unemployment and debt. When elated, manic-depressives commonly behave in ways that perturb those close to them; promiscuity, distressing extravagance, aggression and/or argumentative unpleasantness. When depressed they can be un-inspiringly dependent, unproductive and obstructive. Yet whether or not the condition results in creative genius, or obscurity, destitution and loneliness, is likely to depend much more upon the details of the ways in which these personal vagaries are expressed and received in the individual's immediate social circle than it does upon the mood swings themselves, or the genetic endowment that may be responsible for them. Perhaps the therapeutic issue, then, should be not so much "how can the mood swings be prevented?", but more "what can be done to ameliorate their social impact?". Lithium carbonate has been used to stabilise mood as currently, for nearly half a century. Whether its valuable but imperfect effects can be improved upon by using a different mood stabiliser is still a point of clinical uncertainty, justifying a major randomised controlled clinical trial (Geddes \& Goodwin, 2001). Thus, forty years of biomedical research may have identified some of the genetic underpinnings of Bipolar Affective Disorder, but they have yet to lead to 
A utilitarian perspective

further advances in biomedical treatment. From a utilitarian perspective the merits of a medical/diagnostic approach are limited. Therapeutic improvement is more likely to be advanced by approaches from the social sciences, assisting clarification of how society accommodates and responds to someone prone to excesses of behaviour, and what might be realistically done to ameliorate their consequences. Amongst others, contributions to this perspective are likely to come from endeavours exploring holistic perceptions of the individual (e.g. Tew 2002), analyses of social interaction (e.g. Bennett \& Sani 2004) and professional/lay interactions that underpin meanings of illness (e.g. Maynard \& Frankel 2006). A critical realist framework argues that these have no less epistemological validity than bio-medical contributions, though the habitual construction of Bipolar Affective Disorder as an illness tends to weigh against this in practice.

\section{PANIC DISORDER:}

In formal diagnostic terms this refers to unexpected episodes of intense fear. These are associated with avoidance behaviour and/or frequent recourse to medical advice and emergency medical facilities. Characteristically (but not exclusively) the condition afflicts women of childbearing years and it is associated with the "agoraphobic, housebound housewife". Under different names Panic Disorder has been recognised from the time of Celsius. In men it presented a challenge to military doctors during the American Civil War, where it was known as Da Costa's Syndrome, and during the First World War where it was known as Disorderly Action of the Heart. There have been several physiological formulations of the condition, including those based upon mitral valve prolapse, lactate intolerance, abnormalities of vestibular and chemoreceptor mechanisms, sensitivity to certain peptides such as cholecystokinin, and disturbances of brain noradrenergic and serotonergic mechanisms (Middleton, 1998). Panic Disorder is also one of the many socalled neurotic conditions whose occurrence and sensitivity to treatment are associated with the degree of pre-morbid, formally measured neuroticism (Duggan et al 1995), which itself is measurably partially inherited (Sullivan \& Kendler 1998), and has been 
A utilitarian perspective

found to be associated with the genetic underpinnings of variances in serotonin transporter mechanisms (Munafo et al., 2006).

Interest in a physiological formulation of panic disorder and earlier observations that tricyclic antidepressants are of some value in its treatment have supported a pharmacological approach which is still is the main thrust of treatment in many circles. However this is not universally effective, and the last 25 years have seen a parallel programme of investigative research and clinical trials based upon a clear psychological formulation of panic disorder that informs an effective psychological treatment, Cognitive Behaviour Therapy or CBT (Clark, 1986). A meta-analysis of 35 studies investigating the efficacy of CBT for Panic Disorder published between 1979 and 1996 has established that treatment based upon this framework is effective against a variety of measures (Oei et al., 1999). Direct comparisons with drug treatments have been inconclusive for methodological reasons, but CBT is the recommended treatment in NHS settings (National Institute for Clinical Excellence, 2004a).

Despite this strength of evidence and formal recommendations CBT has yet to make a significant impact upon levels of disability attributable to Panic Disorder. This stands in stark contrast to the rapidity with which new medical treatments for peptic ulceration; proton pump inhibitors and antibiotics directed at Helicobacter, have been adopted over the same period of time. One reason for this might be that the condition is not as systematically recognised as an equally common physical condition might be.

A frequent pattern amongst young women with Panic Disorder is to become expressively concerned for their own safety, and make intense demands of close family. These are frequently translated into a desperate and disruptive search for medical explanation and treatment. The result is a chaotic and demanding family.

In young men the condition is frequently expressed as explosive, demanding helpseeking behaviour. Expectations of resilience and self dependence are threatened by the experience of vulnerability that accompanies panic attacks. This leads to episodic loss of composure, and impulsive and not uncommonly ill-judged demands for treatment. The result is an angry young man. 
A utilitarian perspective

The older, perhaps domestically responsible woman is likely to respond in a different way. For her there are tensions between her own insecurity, and her need to support and provide for others. These tend to find expression in a more secretive experience of panic attacks, and to the development of strategies such as the characteristic avoidance pattern of Agoraphobia. They might provide a sense of mastery of the situation, but only at the expense of important domestic tasks such as shopping independently or providing school transport. These impairments have an obvious impact upon family life and marital harmony.

The older man, and perhaps the older woman whose life is not rooted in family responsibilities, might guard themselves from the risk of occupational disgrace by secretively developing reassurance-seeking strategies, such as a dependence upon medication, social avoidance or a highly structured routine. In their own ways these bring their social costs.

It is not immediately obvious that the clamouring, frightened teenage girl and her family; the angry explosive young man; the dependent, worried and scurrying housewife; the defensive, somewhat reclusive and rigid older man, or the forthright and apparently successful career woman with a bottle of valium tablets in her handbag are all suffering from the same condition. It is equally unlikely that all five of them will have the same shared understanding of their needs and difficulties, as might be the case if all five of them had a broken leg. Nevertheless careful enquiry will reveal that all three are primarily concerned with the fact that they suffer seemingly inexplicable paroxysms of overwhelming fear that threaten their wellbeing and integrity, and against which they have to take precautions. The research tradition that has resulted in the most effective approach (CBT) to these panic attacks is one that recognises and focuses upon their categorical, across case similarities. Thus, in the case of Panic Disorder there is strong evidence to support the utility of a medical/diagnostic framework. Although recurrent panic attacks are associated with a variety of forms of social and emotional distress and disability, these are identifiably secondary to a specific psychological disability; an acquired propensity to interpret certain bodiliy sensations as life-threatening. Panic 
A utilitarian perspective

attacks are susceptible to a generic treatment based upon this formulation, and the sufferer is ill-served by failures to "diagnose" and treat accordingly. Here utility is best served by emphasising the illness model and advancing ways in which individual sufferers and practitioners might better recognise the remediable dysfunction, rather than focusing upon the social consequences with which it commonly presents and in terms of which it still tend to be framed. Again, a critical realist approach emphasises that formulations based upon ideographic social constructions of each case have no greater epistemological validity than the diagnostic, "underpinning disorder" perspective, which in this case offers a route to a strongly evidence-based treatment.

\section{PRIMARY CARE PSYCHIATRY AND THE MANAGEMENT OF DISTRESS:}

The vast majority of people with mental health problems are managed in primary care settings (Goldberg \& Huxley, 1992). Mental health problems make up some $30 \%$ of all consultations in primary care settings, and of these a high proportion are so-called subthreshold disorders (Pincus et al., 1999). What is typically meant by this is significant levels of subjective personal distress without associated features that enable a firm diagnosis or classification. Efficacy of an intervention can only be estimated if there is some consistency about the condition for which it is being applied. Diagnosis provides this, forming an essential underpinning of the Randomised Controlled Clinical Trial (RCCT). RCCTs are meaningless without explicitly stated diagnostic criteria. It is not meaningful to comment upon the effectiveness of a treatment unless it is being applied to an explicitly defined set of complaints and symptoms. As the majority of so-called common mental health problems making up the large number managed in primary care settings do not meet diagnostic criteria, evidence supporting medical treatments does not apply. This has been confirmed by a failure to find applicable evidence in the course of developing NICE Guidelines for the Management of Depression (National Institute for Clinical Excellence, 2004b).

Even though there is no evidence base for medical treatment of these common conditions, they do present in a medical setting, where the predominant response and 
A utilitarian perspective

expectations are the application of a treatment. The selective serotonin re-uptake inhibitors (SSRIs) have been presented as a seemingly non-toxic medicament. Their manufacturers have an understandable commercial interest in promulgating their use. The result has been a broadening of the use of the term "depression", and an enabling effect upon the use of antidepressants (Healy \& Cattell 2003).

Callahan and Berrios (Callahan \& Berrios, 2005) draw attention to the longstanding propensity of people to turn to the doctor when in distress. Doctors respond to this in ways that reflect the Zietgeist. Across the twentieth century a variety of tonics were used before antidepressants and benzodiazepines became available, benzodiazepines in large quantities until their potential for abuse and persisting psychological harm became apparent and, over the last couple of decades the (initially) seemingly harmless SSRIs.

The experienced practitioner might privately acknowledge that prescribing a tonic, a benzodiazepine or an antidepressant at times of emotional distress is an act of placebo, but that cannot be explicitly expressed. The recipient of such a prescription acquires the not-so implicit communication; that the condition they have sought help for is, respectively, a state of being metabolically or nutritionally run down, a state of morbid nervousness, or "depression".

Too often this is an inaccurate and unhelpful portrayal. Causes of psychological distress, personal demoralisation, difficulties with decision making, or a sense of entrapment and powerlessness are legion. Generally, such states are not due to a deficiency of trace nutrients, tranquilizers or antidepressants. Furthermore, prescribing for them is not necessarily harmless, even if the medication itself is pharmacologically inert. Prescription can be experienced as acknowledgement of distress on the part of the doctor, and in that sense potentially supportive and empowering. On the other hand acquisition of the role of "patient" is intrinsically disempowering (Parsons, 1951), and as such threatens to undermine or distract from other approaches to the difficulty.

General practitioners are frequently caught in this uncomfortable trap. Doctors only informally carry authority as counsellor, carry no authority as spiritual advisor, and have relatively limited access to sources of practical support that are available to social 
A utilitarian perspective

workers, financial advisers, solicitors, volunteers, child support agencies, or the police. Their only legitimate professional authority is based upon training and practice in the identifying and treatment of disease. All too often they are faced with having to choose between regretfully acknowledging that they are no more able to provide help than the desperate patient themselves, or risking further disempowerment by defining them as "ill".

In the primary care setting the relationship between psychiatry and social sciences might be most usefully focused upon structural issues. Turning to the doctor when in distress is understandable when there is nowhere else to go. From a utilitarian point of view the enhanced suffering and disability this occasions are more likely to be alleviated by a better understanding of the needs and nature of those who have become overwhelmed by every day events, and developing more suitable ways of providing for them, than continuing to "diagnose" and refine "treatment".

\section{CRITICAL REALISM AND A UTILITARIAN PERSPECTIVE UPON RESEARCHING THESE CONDITIONS}

The orthodox medical position gives primacy to a biomedical perspective. It acknowledges the reality of social deficits and disabilities amongst those with mental health difficulties. However, it also sees them as a secondary consequence of medical phenomena which, if corrected, will result in their spontaneous resolution independent of further intervention. Our three examples draw attention to the fact that this not so simple.

The Manic-Depressive may well have that condition because they have inherited a particular set of genes, and that inherited propensity may well have given rise to the instability of mood regulation that characterises the condition. Neither of these, alone, is sufficient to explain why a particular individual might be a creative genius, a dependent invalid, a misanthropic recluse or commit suicide. A critical realist position reminds us that other perspectives and intellectual traditions have no less epistemological validity than the biomedical perspective. The evidence is that interventions based upon 
A utilitarian perspective

biomedical research have only limited efficacy and more might accrue from closer attention to research grounded in a social sciences perspective..

Panic Disorder research has identified a psychological model which is highly specific and defines a psychological therapy of proven effectiveness. Despite this, social features of presentation, and public and professional attitudes to psychological disorder, continue to exert a powerful effect upon the extent to which its potential for reducing Panic Disorderrelated disability is unlocked. In this instance we argue in favour of the "medical" or "diagnostic" model which, in practice, in this condition, tends to be under-emphasised.

Every day large numbers of people consult their GP in search of assistance with distress quite evidently attributable to social difficulties; the condition of undifferentiated mental and/or emotional distress or what we have referred to as "Primary Care Psychiatry". Under these circumstances it is rarely productive to apply a medical diagnosis and treatment, but the socially and politically determined position of the doctor limit available responses, and frequently encourage potentially harmful medicalisation. In this instance a critical approach draws attention to the fact that conventional practice reflects the professional alignment of the practitioner rather than the needs of the subject .

\section{RECENT RELEVANT UK NHS POLICY DEVELOPMENTS:}

There are reassuring signs that a more pluralist and pragmatic approach to mental health care policy and research is developing. In the UK, 1999 saw the publication of a National Service Framework for Mental Health (Department of Health, 1999), and shortly after that, "The NHS Plan" (Department of Health, 2000). This was a government undertaking to:

- Invest in the NHS.

- Develop a service centred around patient's needs rather than traditions of provision.

- Develop the National Institute for Clinical Excellence (NICE) to review the suitability of treatments made available by the NHS.

- Integrate activities with social services providers. 
A utilitarian perspective

- Extend and flex professional roles.

- Focus expansion upon key services that impact upon common problems affecting large numbers of people, in particular mental health services.

In many ways these policy developments have been re-iterated in the 2006 White Paper; "Our Health, Our Care, Our Say", (Department of Health 2006a), which also emphasised a patient-focused direction of policy travel.

The NSF outlined standards that should be met to address a wide range of mental health issues. The investment in mental health services promised in "The NHS Plan" was made available against the development of additional, functionally specialised community mental health teams; Assertive Outreach Teams, Crisis Resolution/Home Treatment Teams, Early Interventions for Psychosis, and Primary Care Liaison. Prescriptive Policy Implementation Guidance was published and service redesign to these specifications has been a main priority for NHS mental health provider organisations across the country for the ensuing 5 years. Investment in adult mental health services has grown by some $20 \%$ over and above inflation (Department of Health, 2005a) and there are promising signs that these changes are making an impact upon outcomes (Appleby, 2004).

These policy changes and their related service developments have been supported by investment in a developmental infrastructure. Initially under the name of the National Institute for Mental Health in England (NIMHE), and more recently re-formed as the Care Services Improvement Partnership (CSIP), eight regional centres have been resourced to support the implementation of these and related NHS mental health policy developments. The national and regional activities of CSIP/NIMHE are a set of programmes which provide local publicity, professional peer support and information exchange intended to influence practitioners' and provider organisations around a finite set of areas of service change, activity and development issues. Although the full academic implications of these have yet to be realised, they do present a strong challenge to an exclusively diagnostic/medical sciences-based approach to mental health policy and practice. They include programmes of work focusing upon; 


\section{Gender, Black and Minority Ethnic Groups Issues.}

It has long been recognised that minority ethnic groups, particularly Afro-Caribbean young men, are excessively represented amongst the psychiatric inpatient population, amongst those that are formally detained in mental health institutions and amongst those that are given high doses of sedating medication under such circumstances (Harrison et al., 1988, Shaw et al., 2006). A variety of explanations have been advanced but it is now generally accepted (Morgan et al., 2005), that this cannot be explained on the basis of a truly higher rate of psychosis amongst this racial sub-group. It has to be understood, at least in part, as an expression of cultural misunderstanding. Critical evaluation of this demands the input of social scientists.

The proportion of women users of mental health services is higher than raw population statistics would predict. There is no reason to believe that inheritable vulnerabilities contributing to the risk of developing a mental health difficulty are systematically sex linked. Excess incidence of mental health difficulties amongst women has to be understood as a reflection of gender inequalities and the patriarchal nature of society (Williams 2005). There are specific issues arising from interactions between responsibilities for child care and mental health difficulties, the impact of physical and sexual abuse and occupational disempowerment that are all peculiar to women.

Public health perspectives demand much closer attention to the needs of these seemingly vulnerable sub-groups. There is need for a much more systematic research into the social vulnerabilities and specifics of relationships between "mental health problems" and social vulnerability. For instance, the Asian community has a particular issue in the form of probably depressed, certainly withdrawn and isolated married women (Hussain \& Cochrane, 2004) which has sociological rather than medical determinants (Burman et al. 2002). It is therefore encouraging that these are concerns currently being addressed in government policy from a social scientific, as well as a medical, perspective (Department of Health, 2002, 2005b). 
A utilitarian perspective

\section{Social Inclusion}

In 2004 the Social Exclusion unit of the Office of the Deputy Prime Minister published "Mental Health and Social Exclusion" (Social Exclusion Unit, 2004). The essence of the report was to draw attention to the fact that people with mental health difficulties continue to suffer stigma and discrimination, and as a result are unreasonably disabled in their ability to access employment, education and other elements of a socially included and economically productive life. Although there is nothing new or unexpected in this finding, the fact that it has attracted the interest of senior policy makers is of relevance, and the report has stimulated Department of Health funded programmes facilitating the delivery of its recommendations.

Significant amongst these are anti-stigma campaigns, attempts to address employers' reluctance to employing individuals with a history of mental health difficulties, direct payment issues, the particular difficulties faced by local authority housing officers faced with the issues sometimes generated by people with mental health difficulties and the conundrums generated by user and carer led services. These important areas of service change and development are not going to be informed by medical science but certainly can, and in some places are, being informed by social scientists (e.g. Wistow \& Schneider, 2003).

\section{Recovery}

The traditional medical approach to mental health difficulties regards the goal of treatment to be resolution of symptoms, in particular improvements in symptom ratings or changes in the outcome of a structured interview. Subjective accounts by people suffering from mental health difficulties, and other observations suggest that much more is involved in the restitution of someone with a mental health difficulty. The medical approach to mental health difficulties explicitly identifies the sufferer as a person with "something wrong with them". Though often diligently and very well-meaningly applied, this approach inadvertently subverts the patient's autonomy and sense of worth by continuing to describe them in such terms, and act towards them accordingly, maintaining the social deficits associated with the status of "psychiatric patient". As is 
A utilitarian perspective

exemplified by successful para-athletes, "Recovery" does not necessarily depend upon eradication of symptoms or sources of disability. It refers instead to a process of personal growth enabling reacquisition of a sense of self worth, autonomy and minimised dependency (Davidson \& Strauss, 1992). It is essentially a social construct relating to the association between self and society. It is widely promulgated in mental health services in other parts of the world. The recent Department of Health review of mental health nursing explicitly places "Recovery" at the heart of their underpinning values (Department of Health, 2006b).

\section{Acute Care}

However carefully designed, socially aware and culturally sensitive provision of mental health services might be, there will be times when the assurance of personal and public safety mandate provision of 24 hour care and supervision. Occasionally there will be inescapable instances of the need to conduct this irrespective of patients' expressed wishes. This poses particular difficulties in relation to human rights (e.g. Bartlett, 2005), and resonates with historical perceptions of the nature and purpose of mental health services.

The current state of acute psychiatric inpatient services has been roundly criticised by several reports of recent years, most recently the $11^{\text {th }}$ Biennial Report from the Mental Health Act Commission (Mental Health Act Commission, 2006). Important criticisms are; a frequent lack of clarity over the purpose of admission, unsatisfactory living conditions, an experienced atmosphere of coercion, threat and intimidation; and a lack of therapeutic engagement by staff distracted by paperwork and procedural demands. There is undue emphasis upon risk containment at the expense of measures designed and intended to facilitate recovery, and restitution to a sufficiently high level of autonomy to permit a return to community living.

The need to transfer an individual's care from their community setting to a 24 hour facility is invariably occasioned by socially determined developments such as perceptions of risk and safety, public expectations, and exhaustion of formal and informal carer's 
A utilitarian perspective

availability to provide in a less restricted setting. From a utilitarian view of knowledge development this is perhaps where acute-care relevant research should be focused.

\section{New Ways of Working}

At the time of writing some $11 \%$ of General Adult Psychiatry posts across England are either vacant or occupied by expensive locums of variable ability.

This unsatisfactory state of affairs has been explored through interviews with some 26 incumbent psychiatrists practicing in NE England (Kennedy and Griffiths, 2001). They found a wide range of approaches, reducible to a pair of stereotypes:

- Consultant "T" (traditional) maintained a high personal caseload, felt directly responsible for all that happened with patients "under" them, and conducted a routine that included a large proportion of fixed commitments and tended to be demoralised and unsatisfied.

- Consultant " $\mathrm{N}$ " (new) had adopted a more consultative style; distributing responsibility and offering advice and support to others in the multi-disciplinary team rather than directly intervening with patients and was more satisfied with their lot.

These reflections have been echoed by others concerned that the psychiatrist's traditional approach undermines and conflicts with the principles of multi-disciplinary team working. The result is a New Ways of Working (NWW) programme, which is focussed upon clarifying and enabling ways in which the various professions; Psychiatry, Nursing, Social Work, Psychology, Occupational Therapy and others might contribute to a multidisciplinary approach to service provision. The first explicit output from that programme is recommendations about the role of the Consultant Psychiatrist (Royal College of Psychiatrists \& National Institute for Mental Health (England), 2005). This document challenges the traditional position of the Consultant Psychiatrist as ex officio team leader, manager or sapient head. It draws into question the grounds upon which that assumed seniority has been based and it is challenging orthodoxies in the professional relationships between consultants and others. This work, essentially concerning the nature, composition and conduct of multi-disciplinary teams providing 
A utilitarian perspective

medical and social care has already been the subject of some social sciences research (Carpenter et al.,2003; Onyett et al., 1994; Paxton et al., 2003), but a full and more systematic investigation of the relationships between team function and therapeutic outcomes has yet to begin.

\section{Improving Access to Psychological Therapies.}

Mental health difficulties are now recognised as the single most common reason for absence from work due to sickness, and dependence upon Incapacity Benefit. The economic implications of this have not gone unnoticed. Lord Layard has drawn attention to the fact that many of the individuals so affected could be returned to economic productivity were there readier availability of psychological therapies supporting restitution of their difficulties and a return to work (Layard, 2005). In this context the term "Psychological Therapies" refers to a stepped care provision of interventions, from simple practical support and advice through more structured, guided self-help procedures to formal psychological treatment, of the kind outlined for the treatment of panic disorder earlier in this paper.

Although it is presented as a need to improve the nation's health by further investing in healthcare provision, this development can also been seen as a major piece of welfare reform. As we have argued, many of those presenting in primary care settings and acquiring the label (and benefits) of "mental illness" are perhaps not best served by that process. Layard's proposal addresses this by suggesting that a significant proportion of disability and economic dependency can be reversed by the provision, not of additional medical resources, but of emotional support, understanding, access to practical help and where appropriate, more formal psychological therapies.

This is probably the strongest statement to date that it is not just frustrated social scientists, disappointed service users and a small number of dissident psychiatrists who feel there is much more to the research and management of so-called mental health difficulties than medical sciences alone can provide. What has hampered contributions from outside of medicine, to date, is the polarised nature of the debate. More often than not such polarisations owe more to vested interest and defensive posturing than they do 
A utilitarian perspective

to a true spirit of investigation or intellectual rigour. David Pilgrim and Anne Rogers have already drawn attention to the fact that from a critical realist position, multiple perspectives upon a particular area of enquiry reflect strengthened rather than weakened intellectual rigour (Pilgrim \& Rogers, 2005). That has to be particularly true in relation to the study and therapeutic response to emotional and/or mental distress which legitimately involve lived experiences, lay/community/historical perspectives and differing professional perspectives. Each of these perspectives is exerted within a set of power relations within which the distressed subject gets caught up, and yet from a critical realist position, none has epistemological priority. Best policy and practice can only be achieved by acknowledging this and basing choices of provision upon informed debate about the relative utility of each, in a given situation. 
A utilitarian perspective

\section{References}

Appleby, L. (2004) The National Service Framework for Mental Health - Five Years On., London: Department of Health www.dh.gov.uk/publicationsandstatistics

Barnes B., Bloor D., \& Henry, J. (1996) Scientific Knowledge: A Sociological Analysis. London: Athlone Press

Barrett, T.B., Hauger, R.L., Kennedy, J.L., Sadovnick, A.D., Remick, R.A., Keck, P.E., McElroy, S.L., Alexander, M., Shaw, S.H., Kelsoe, J.R. (2003). Evidence that a single nucleotide polymorphism in the promoter of the $G$ protein receptor kinase 3 gene is associated with Bipolar Disorder. Molecular Psychiatry, 8(5), 546-57.

Bartlett, P. (2005). Introduction to "Special Edition on Human Rights and Mental Disorder". International Journal of Law and Psychiatry, 28, 97-98.

Bateson, G. (1972) Steps to an Ecology of Mind. San Fransisco: Chandler Publishing Company.

Bennett, M. \& Sani F (2004). The Development of the Social Self. Hove: Psychology Press.

Bentall, R. (2006). Madness Explained: Why we must reject the Kraeplinian paradigm and replace it with a "complaint-orientated" approach to understanding mental illness. Medical Hypothesis, 66, $220-233$.

Bhaskar, R. (1975) A Realist Theory of Science: 2nd edition. London: Verso.

Bracken, P. \& Thomas, P. (2001). Postpsychiatry: a new direction for mental health. British Medical Journal, 322, $724-727$. 
A utilitarian perspective

Burman, E, Chantler K, Batsleer J (2002) Service responses to South Asian women who attempt suicide or self harm: challenges for service commissioning and delivery. Critical Social Policy, 22, 641-668.

Busfield, J. (1989) Managing Madness: Changing Practice and Ideas. London: Unwin Hyman

Callahan, C. \& Berrios, G. (2005) Reinventing Depression. A History of the Treatment of Depression in Primary Care 1940-2004. New York: Oxford University Press Inc.

Carpenter, J., Schneider, J., Brandon, T. \& Wooff, D. (2003). Working in multidisciplinary Community Mental Health Teams: The impact on social workers and health professionals of integrated mental health care. British Journal of Social Work, 33, 1081-1103.

Clark, D.M. (1986). A cognitive approach to panic. Behaviour Research \& Therapy. 24, 461-470.

Davidson, L. \& Strauss, J. (1992). Sense of self in recovery from severe mental illness. British Journal of Medical Psychology, 65, 131 - 145.

Department of Health (1999). National Service Framework For Mental Health. London: The Department of Health. www.dh.gov.uk/publicationsandstatistics

Department of Health (2000). The NHS Plan - A Plan for Investment. A Plan for Reform. London: Department of Health. www.dh.gov.uk/publicationsandstatistics

Department of Health (2002). Women's Mental Health into the Mainstream: Strategic Development of Mental Health Care for Women. London: Department of Health. www.dh.gov.uk/publicationsandstatistics 
A utilitarian perspective

Department of Health \& Mental Health Strategies (2005a). The 2004/5 National Survey of Investment in Mental Health Services. London: Department of Health. www.dh.gov.uk/publicationsandstatistics

Department of Health (2005b). Delivering Race Equality in Mental Health Care. London: Department of Health. www.dh.gov.uk/publicationsandstatistics

Department of Health (2006a) Our Health, Our Care, Our Say. London: Department of Health www.dh.gov.uk/publicationsandstatistics

Department of Health (2006b) From values to action: The Chief Nursing Officer's review of mental health nursing. London: Department of Health www.dh.gov.uk/publications andstatistics

Double, D. (2002). The limits of psychiatry. British Medical Journal, 324, $900-904$.

Duggan, C., Sham, P., Lee, A., Mime, C. \& Murray, R. (1995) Neuroticism: a vulnerability marker for depression. Evidence from a family study. Journal of Affective Disorders 35 139143.

Geddes, J. \& Goodwin G. (2001). Bipolar Disorder: clinical uncertainty, evidence-based medicine and large-scale randomised trials. British Journal of Psychiatry, 178 (Supp 41), s191-s194.

Goldberg, D. \& Huxley, P. (1992) Common Mental Disorders. London: Routledge

Harrison, G., Owens, D., Holton, A., Neilson, D. \& Boot, D. (1988). A prospective study of severe mental disorder in Afro-Caribbean patients. Psychological Medicine. 18, 64357. 
A utilitarian perspective

Healy, D. \& Cattell, D. (2003). Interface between authorship, industry and science in the domain of therapeutics. British Journal of Psychiatry, 183, $22-27$.

Hussain, F. \& Cochrane, R. (2004). Depression in South Asian women living in the UK: a review of the literature with implications for service provision. Transcultural Psychiatry, 4, 253-70.

Jones, K. (1972) A History of the Mental Health Services. London : Routledge and Kegan Paul

Kennedy, P. \& Griffiths, H. (2001). General psychiatrists discovering new roles for a new era ... and removing work stress. British Journal of Psychiatry. 179, 283-285.

Law, J. \& Mol, A. (2002) Complexities: Social Studies of Knowledge Practices. Durham NC : Duke University Press

Layard, R. (2005) Happiness: Lessons from a New Science. New York : Penquin Books

Maynard, D. \& Frankel R (2006) On diagnostic rationality: bad news, good news, and the symptom residue. In Heritage $J$ \& Maynard D, (Eds). Communication in Medical Care. Interactions between primary care physiciains and patients. Cambridge: Cambridge University Press pp $248-278$.

Mental Health Act Commission (2006) In Place of Fear? Eleventh Biennial Report. London : TSO

Middleton, H.C. (1998). Panic disorder: a theoretical synthesis of medical and psychological approaches. Journal of Psychosomatic Research. 44, 121-32. 
A utilitarian perspective

Morgan, C., Mallett, R., Hutchinson, G., Bagalkote, H., Morgan, K., Fearon, P., Dazzan, P., Boydell, J., McKenzie, K., Harrison, G., Murray, R., Jones, P., Craig, T. \& Leff, J. (2005). AESOP Study Group. Pathways to care and ethnicity. 1: Sample characteristics and compulsory admission. Report from the AESOP study. British Journal of Psychiatry, $186,281-289$.

Munafo, M., Clark, T., Roberts, K. \& Johnstone, E. (2006). Neuroticism mediates the association of the serotonin transporter gene with lifetime major depression Neuropsychobiology, 53, 1-8.

National Institute for Clinical Excellence (NICE). (2004a) Clinical Guidelines for the Management of Anxiety. London: National Institute for Clinical Excellence www.nice.org.uk

National Institute for Clinical Excellence (NICE) (2004b) The Management of Depression in Primary and Secondary Care. London: National Institute for Clinical Excellence www.nice.org.uk

Oei, T.P., Llamas, M. \& Devilly, G.J. (1999). The efficacy and cognitive processes of cognitive behaviour therapy in the treatment of panic disorder with agoraphobia. Behavioural and Cognitive Psychotherapy, 27, 63-88.

Onyett, S., Heppleston, T. \& Bushnell, D. (1994). A national survey of community mental health teams: Team structure and process. Journal of Mental Health, 3, 175-194.

Parsons, T. (1951) The Social System. Glencoe, Illinois : The Free Press 
A utilitarian perspective

Paxton, R., Chaplin, L., Selman, M., Liddon, A., Cramb, G. \& Dodgson, G. (2003). Early intervention in psychosis: A pilot study of methods to help existing staff adapt. Journal of Mental Health, 12, 627-636,

Pilgrim, D. \& Rogers, A. (2005). The troubled relationship between psychiatry and sociology. International Journal of Social Psychiatry, 51228 - 241.

Pincus, H.A., Davis, W.W. \& McQueen, L. (1999). "Subthreshold" mental disorders. A review and synthesis of studies on minor depression and other "brand names". British Journal of Psychiatry, 174, 288-298.

Redfield Jamison, K. (1993) Touched with Fire: Manic-depressive Illness and the Artistic Temperament. New York : Macmillan

Royal College of Psychiatrists \& National Institute for Mental Health in England. (2005) New Ways of Working for Psychiatrists: Enhancing effective, person centred services through new ways of working in multidisciplinary and multi-agency contexts. London : Department of Health www.dh.gov.uk/publicationsandstatistics

Scull, A.T. (1989) Social Order/Mental Disorder. Anglo-American Psychiatry in Historical Perspective. Berkley: University of California Press

Shaw, I., Middleton, H. \& Cohen, J. (2006). Treatment Without Consent: An Investigation into the work of the Mental Health Act Commission. Aldershot : Ashgate Press, Forthcoming.

Social Exclusion Unit (2004) Mental Health and Social Exclusion. London : Office of the Deputy Prime Minister www.socialexclusionunit.gov.uk/publications 
A utilitarian perspective

Sullivan, P.F. \& Kendler K.S. (1998) Genetic epidemiology of "neurotic" disorders. Current Opinion in Psychiatry 11 143-147.

Tew, J. (2002) Going social: Championing a holistic model of mental distress within professional education. Social Work Education 21 143-155

Williams J (2005) Womens' mental health: taking inequality into account. In Tew J (Ed) Social Perspectives in Mental Health: Developing Social Models to Understand and Work with Mental Distress. London: Jessica Kingsley Publishers.

Wistow, R. \& Schneider, J. (2003) Users' views on supported employment and social inclusion: a qualitative study of 30 people in work. British Journal of Learning Disability $31,166-174$. 